\title{
Maltreatment Risk among Children with Disabilities
}

Miriam J Maclean ${ }^{\mathrm{a}}$, BPsych(Hons), MSc, PhD, Scott Sims ${ }^{\mathrm{a}}$, MBiostat, BSC, Carol Bower ${ }^{\mathrm{a}}$, MSC, MB BS PhD, FAPHM, Helen Leonard ${ }^{\mathrm{a}}$, MBChB, MPH, Fiona J Stanley ${ }^{\mathrm{a}}$, MD, MSC, FFPHM, FAFPHM, Melissa O’Donnell ${ }^{\mathrm{a}}$, BPsych(Hons), MPsych, Dip Ed, PhD

Affiliations: a. Telethon Kids Institute, University of Western Australia, Perth, Western Australia.

Address correspondence to: Melissa O'Donnell, Telethon Kids Institute, University of Western Australia, 100 Roberts Road, Subiaco, Australia, 6008. Telephone: (08) 94897777. Email: Melissa.O'Donnell@telethonkids.org.au

Short Title: Maltreatment Risk among Children with Disabilities

Funding source: This work was supported by an Australian Research Council Linkage Project Grant [LP100200507] and an Australian Research Council Discovery Grant [DP110100967]. Dr Melissa O'Donnell is supported by a National Health and Medical Research Council Early Career Fellowship [1012439].

Financial Disclosure: The authors have no financial relationships relevant to this article to disclose.

Conflict of Interest: The authors have no conflicts of interest relevant to this article to disclose.

\author{
Abbreviations: \\ WA-Western Australia \\ WARDA- Western Australian Register of Developmental Anomalies \\ IDEA- Intellectual Disability Exploring Answers \\ HMDS- Hospital Morbidity Data System \\ MHIS- Mental Health Information System \\ ICD- International Classification of Disease \\ CPFS- Department of Child Protection and Family Support \\ HR- Hazard Ratio, CI- Confidence Interval \\ ID- Intellectual Disability \\ DS- Down syndrome
}

\section{Table of Contents Summary}

Children with disabilities are at increased risk of maltreatment and this population-based study determines whether risk varies by type of disability.

\section{What is known:}

Children with disabilities experience elevated rates of child abuse and neglect. Only a few population-based studies have been conducted producing mixed evidence regarding maltreatment risk for children with different types of disabilities.

\section{What this study adds:}

Children with disabilities account for one in three substantiated maltreatment allegations, however maltreatment risk was not consistent across all disabilities. Children with intellectual 
disability, mental/behavioural problems and conduct disorder had increased risk but not autism, Down syndrome or birth defects. 


\section{Contributors' Statement Page}

Miriam Maclean conceptualised and designed the study, drafted the initial manuscript and approved the final manuscript as submitted.

Scott Sims carried out the initial analyses, reviewed and revised the manuscript and approved the final manuscript as submitted.

Dr Carol Bower, Dr Helen Leonard and Dr Fiona Stanley contributed to the design of the study, reviewed and revised the manuscript and approved the final manuscript as submitted.

Dr Melissa O'Donnell contributed to the conceptualisation and design of the study, critically reviewed the manuscript and approved the final manuscript as submitted. 


\begin{abstract}
Background: Children with disabilities are at increased risk of child maltreatment however there is a gap in the evidence about whether all disabilities are at equal risk and whether risk factors vary according to the type of disability.
\end{abstract}

Methods: A population-based record-linkage study of all children born in Western Australia between 1990-2010. Children with disabilities were identified using population-based registers and risk of maltreatment determined by allegations reported to the Department for Child Protection and Family Support.

Results: While children with disabilities make up 10.4\% of the population they represent $25.9 \%$ of children with a maltreatment allegation and $29 \%$ of those with a substantiated allegation. However increased risk of maltreatment was not consistent across all disability types. Children with intellectual disability, mental/behavioural problems and conduct disorder continued to have increased risk of an allegation and substantiated allegation after adjusting for child, family and neighbourhood risk factors. In contrast, adjusting for these factors resulted in children with autism having a lower risk, and children with Down syndrome and birth defects/cerebral palsy having the same risk as children without disability.

Conclusions: The prevalence of disabilities in the child protection system suggests a need for awareness of the scope of issues faced by these children and the need for interagency collaboration to ensure children's complex needs are met. Supports are needed for families with children with disabilities to assist in meeting the child's health and developmental needs, but also to support the parents in managing the often more complex parenting environment. 


\section{Introduction}

An estimated $5.1 \%$ of children worldwide have a moderate to severe disability ${ }^{1}$. Research shows that children with disabilities experience elevated rates of child abuse and neglect ${ }^{2-6}$. However there are critical knowledge gaps leading United States researchers Kendall-Tackett to state "there is an appalling gap in the states' ability to protect abused and neglected children with disabilities"

At the most basic level, states/countries need to know the proportion of children within their child protection systems who have disabilities, and their types of disability ${ }^{7}$. Risk of maltreatment is associated with child characteristics such as age and ethnicity, parent factors such as young age, mental health problems and substance abuse, and neighbourhood factors such as socioeconomic disadvantage ${ }^{6}$. Families of children with disabilities more frequently experience risk factors associated with a higher risk of maltreatment ${ }^{8}$. However, the risk for maltreatment among children with disabilities has not been explored taking into account the multiple risk factors that often co-occur in the context of these families.

The few population-based studies conducted, have produced mixed evidence regarding maltreatment risk for children with different types of disabilities ${ }^{9,4,10}$, and it remains unclear whether disability types, such as intellectual disability (ID), are associated with increased risk. The aims of this research are to: report the prevalence of different disabilities within the child protection system in an Australian state; and to assess risk of maltreatment in various types of disability taking into account child, family and neighbourhood risk factors.

\section{Methods}

\section{Population and Data Sources}


We conducted a population-based record-linkage study of all children born in Western Australia (WA) between 1990-2010 using de-identified administrative data. Disability information was obtained from four sources which had information for the whole study period 1990 to 2010. The first is the Western Australian Register of Developmental Anomalies (WARDA) ${ }^{11}$ which includes structural or functional birth defects that are present before birth and diagnosed by age six, and cerebral palsy. WARDA receives notifications of birth defects from the Midwives Notification System, the Hospital Morbidity Data System and other services, (e.g. genetic, pathology, and private practitioners). The second is the population-based Intellectual Disability Exploring Answers (IDEA) ${ }^{12}$ database which provides WA state data on individuals with ID and/or autism, using information provided by the Disability Services Commission (DSC) for individuals of any age with ID who are provided with services, and the Department of Education (individuals with ID receiving education support, predominantly aged 5-17 years). The IDEA database also collects information on severity of ID and for cases obtained through DSC the probable cause utilising diagnostic information reviewed from medical records. Cases could be classified as caused by chromosomal disorders, metabolic disorders, prenatal exposure to alcohol, postnatal injury, cultural-familial (family history of ID/environmental disadvantage), etc ${ }^{13}$. The third is the Hospital Morbidity Data System (HMDS) which contains information on all public and private hospital discharges, including up to 21 diagnostic codes utilising the International Classification of Diseases (ICD) codes (ICD-9:1990-June 1999, ICD-10: July 1999-2010, see Table 1). The fourth is the Mental Health Information System (MHIS) containing information on all mental health-related public and private inpatient admissions and public outpatient contacts with diagnoses captured using ICD codes. This study has ethics approval from the WA Department of Health Human Research Ethics Committee. 
Disability for this paper was defined as any limitation or impairment which may affect everyday activities ranging from intellectual, physical, and psychological conditions ${ }^{14}$. This broad definition includes psychological conditions, which are often not diagnosed until adolescence, as well as disabilities typically diagnosed at birth or soon after. Children's disabilities were identified through the four data sources of WARDA, IDEA, HMDS and MHIS, and disability groups were categorised as shown in Table 1. Disability categories were chosen as they were consistent with our definition, were the main disability groups identified in the sources and their sample sizes were adequate for analyses. Children could be grouped in more than one category if they had comorbid conditions, however Down syndrome (DS) was grouped separately as it is both a birth defect and causes ID. Of the 54,532 children who had either ID, birth defect/cerebral palsy, autism, conduct disorder, or a mental/behavioural disorder, $15.6 \%$ had one or more comorbidities. For children with ID there was a high rate of comorbidity with other conditions $(62.6 \%)$.

Table 1. Disability Group and their corresponding codes and databases.

\begin{tabular}{|c|c|c|c|}
\hline Group & Databases & ICD-9 codes & ICD-10 Codes \\
\hline $\begin{array}{l}\text { Intellectual } \\
\text { Disability }\end{array}$ & IDEA, HMDS, MHIS & $317-319$ & F70-F79 \\
\hline Down Syndrome & $\begin{array}{l}\text { IDEA, WARDA, } \\
\text { HMDS, MHIS }\end{array}$ & 758.0 & Q90 \\
\hline $\begin{array}{l}\text { Birth } \\
\text { Defects/Cerebral } \\
\text { Palsy (All congenital } \\
\text { malformations and } \\
\text { cerebral palsy) }\end{array}$ & WARDA* & & \\
\hline Autism & IDEA, HMDS, MHIS & 299.0 & F84.0, F84.1 \\
\hline Conduct Disorder & HMDS, MHIS & $312,314.0$ & F90-F92 \\
\hline $\begin{array}{l}\text { Mental and } \\
\text { Behavioural } \\
\text { Disorder** } \\
\text { (All other } \\
\text { mental/behavioural } \\
\text { disorders apart from autism, } \\
\text { conduct disorder, and } \\
\text { intellectual disability). }\end{array}$ & HMDS, MHIS & $\begin{array}{l}290-316 \\
\text { (excluding 299.0, } \\
312,314.0 \text { ) }\end{array}$ & $\begin{array}{l}\text { F00-F69, F80- } \\
\text { F99 } \\
\text { (excluding } \\
\text { F84.0, F84.1, } \\
\text { F90-F92 }\end{array}$ \\
\hline Any Disability & Any of the above & Any of the above & $\begin{array}{l}\text { Any of the } \\
\text { above }\end{array}$ \\
\hline
\end{tabular}

*http://kemh.health.wa.gov.au/services/register developmental anomalies/diagnostic codes birth defects.htm 
**This includes organic disorders, disorders due to psychoactive substance use, schizophrenia type disorders, mood disorders, behavioural syndromes, stress related disorders, personality disorders, specific developmental disorders, behavioural and emotional disorders).

We also included an additional analysis of two birth defect categories from the WARDA: spina bifida $(\mathrm{n}=192)$; and cleft lip and/or palate $(\mathrm{n}=525)$, to compare to previous research ${ }^{15}$. The disability data was linked to records from Births Registrations (1990-2010), the Midwives Notification System (1990-2010), Mortality Database (1990-2010) and the Department of Child Protection and Family Support (1990-2010). Using probabilistic linkage of common identifiers such as name, address and birth date, the data were linked by the Department of Health's Data Linkage Branch where extensive clerical review was also conducted as per their process, with a linkage quality of $97-98 \%{ }^{16,17}$. The identifiers were separated from the clinical or service information to maximise privacy during the linkage process, with only de-identified information provided to researchers.

The child's gender, Aboriginality, birth weight and gestational age were obtained from Births Registrations and Midwives Notification System, along with parents' marital status and age at the time of birth. Neighbourhood-level socio-economic status was determined by the Index of Relative Social Disadvantage from the Australian Bureau of Statistics using the Birth and Midwives data ${ }^{18}$. Five levels of disadvantage were assigned to census collection districts (approximately 200 households) ranging from 1 (most disadvantaged) to 5 (least disadvantaged). Parents' history of hospital discharges and contacts (pre and post-birth) for mental health, substance-related issues and assault-related injuries were ascertained from HMDS and the MHIS (1970-2010). The Mortality Register was used to censor observations at date of death.

The Department for Child Protection and Family Support (CPFS) records provided data on children's entire history of maltreatment allegations from birth onwards including age of 
allegation and type of maltreatment. Allegations consist of reports made to CPFS regarding alleged child abuse and neglect. An allegation is substantiated by CPFS when following investigation there is reasonable cause to believe the child has been, is being, or is likely to be abused, neglected or otherwise harmed. Following a substantiated allegation children could be removed from their families and enter out-of-home care.

\section{Statistical Analysis}

In addition to descriptive analysis, Cox regression was used to estimate the adjusted and unadjusted hazard ratio (HR) and 95\% confidence interval (CI) for the time in months from birth to first maltreatment allegation, adjusted for disability types and other risk factors. Results where the $95 \%$ CIs did not include the null value of 1 were considered statistically significant. Records were censored at their date of death and if there was no child maltreatment allegation by the end of followup. The main analyses firstly assessed the hazard ratio for child maltreatment allegations using a dichotomous disability covariate (disability versus no disability), and secondly using six dichotomous covariates (six disability types) in addition to adjusting for child, family and neighbourhood risk factors. In the categorical disability analysis (6 disability groups) children with comorbidities could be categorised in more than one group (except DS) and analysed accordingly. Further Cox regression analyses investigated time to a substantiated allegation and time to a period of out-of-home care. In our analyses we are assuming the values of these covariates were determined at the point when follow-up began on each child (time $=0$, i.e. at birth) and that these did not change over the period of observation. As we are not confident when diagnoses began we did not add a time varying covariate for disability and have stated this in the limitations. Additional analyses examined risk of allegations related to aspects of ID including severity, comorbidity, cause, and the specific birth defects of spina bifida and cleft lip and/or palate. Further 
analyses were also conducted to investigate type of maltreatment allegation (neglect, physical and sexual abuse) for all disability groups and ID severity (appendix).

\section{Results}

Risk of allegations

Of the 524,534 children in the population cohort, $4.6 \%$ had a maltreatment allegation (Table 2). Overall, $25.9 \%$ of child maltreatment allegations and $29.0 \%$ of substantiated allegations involved a child with a disability. Maltreatment allegations varied by disability type, children with ID comprised $6.7 \%$ allegations, similar to birth defects/cerebral palsy (6.6\%), and conduct disorder $(4.5 \%)$ with the largest number of allegations for children with mental/behavioural disorders (15.6\%). Only a small proportion of allegations included children with Down syndrome $(0.1 \%)$ or autism $(0.7 \%)$.

Age at first maltreatment allegation was similar across disability types with a mean age of 4.8 years, and fairly similar to children without disabilities (4.2 years). Type of maltreatment allegation was also similar across disability groups (neglect $25 \%$, physical abuse $24 \%$, sexual abuse $19 \%$ and emotional abuse $3.5 \%$ ). This pattern was generally similar to children without disabilities, except proportions were slightly higher for neglect and physical abuse. The only groups which varied to a large degree were children with ID who had a higher proportion of neglect (33\%) and children with conduct disorder who had more physical abuse $(31 \%)$.

Prior to adjusting for child, family and neighbourhood characteristics, children with a disability had over a two-fold increased risk of having a maltreatment allegation [Hazard Ratio $(\mathrm{HR})=2.64,95 \% \mathrm{CI}: 2.56-2.74]$ and a three-fold increased risk of a substantiated 
allegation ( $\mathrm{HR}=3.09,95 \% \mathrm{CI}: 2.97-3.22)$ compared to children without a disability (see Table 3). All disability types other than DS were associated with a significantly increased risk for having a maltreatment allegation prior to adjustment. The highest hazard ratios were for conduct disorder $(\mathrm{HR}=5.14,95 \% \mathrm{CI}: 4.83-5.47)$ followed by ID $(\mathrm{HR}=3.86,95 \% \mathrm{CI}: 3.67-4.06)$ and mental/behavioural disorders ( $\mathrm{HR}=3.69,95 \% \mathrm{CI}: 3.56-3.82)$. The risk of substantiated allegation was also higher.

\section{Adjustment for demographic and psychosocial characteristics}

As shown in the appendix, demographic and psychosocial characteristics vary across disability type. Accounting for child, family and neighbourhood risk factors partially attenuated the relationship between disabilities and maltreatment, particularly for conduct disorder and mental/behavioural disorders, and changed the relationship for autism from increased to decreased risk (Table 3). After controlling for other risk factors, children with a disability still had an increased risk of maltreatment allegations (HR=1.74, 95\%CI:1.68-1.80) and substantiated allegations ( $\mathrm{HR}=1.89,95 \% \mathrm{CI}: 1.80-1.98)$ compared to children without disabilities.

Risk was highest for children with intellectual disabilities (HR=2.14, 95\%CI:2.00-2.28], followed by conduct disorder, and mental/behavioural disorders. There was significantly lower risk of maltreatment allegations for children with autism $(\mathrm{HR}=0.74,95 \% \mathrm{CI}: 0.63-0.89)$, and children with DS also had lower risk, although did not reach significance $(\mathrm{HR}=0.69$, 95\%CI:0.46-1.02). Risk of maltreatment allegations did not differ between children with birth defects/cerebral palsy and children with no disabilities (HR=0.99, 95\%CI:0.93-1.05), although they had a slightly elevated risk of a substantiated allegation $(\mathrm{HR}=1.10$, 95\%CI:1.01-1.20) and entering out-of-home care (HR=1.32, 95\%CI:1.18-1.49, see 
appendix). Analysis by type of maltreatment allegation found relatively consistent results with the exception of maltreatment involving sexual abuse, where autism was protective and birth defects/cerebral palsy showed no increased risk. However caution should be taken interpreting results due to smaller sample sizes and therefore unreliable estimates (appendix).

Supplementary multivariate analysis of spina bifida and cleft lip and/or palate was conducted finding an increased risk of substantiated allegation in the univariate analysis $(\mathrm{HR}=1.94$, 95\%CI:1.01-3.72; HR=1.61, 95\%CI:1.01-2.56 respectively) but after adjustment found no increased risk $(\mathrm{HR}=0.74,95 \% \mathrm{CI}: 0.33-1.65 ; \mathrm{HR}=0.81,95 \% \mathrm{CI}: 0.42-1.55$ respectively $)$. Caution should be taken with this finding due to small sample size.

Aboriginal children had an increased risk of a maltreatment allegation almost 6 and a half times compared to non-Aboriginal children. However this risk dropped to 1.64 (95\%CI:1.571.70) once other factors were taken into account, particularly as they had a higher risk of other family and social risk factors. The proportion of Aboriginal children with disability was $14.2 \%$, compared with $10.1 \%$ for non-Aboriginal children. They had a higher proportion of children with ID (3.2\% versus $1.5 \%)$ and mental/behavioural disorder (17.5\% versus $14.3 \%)$, both which had higher risks of maltreatment allegations.

\section{Severity and cause of intellectual disability}

For children with ID, less severe disability was related to increased likelihood of maltreatment allegations (Table 4). After controlling for other risk factors, children with borderline-mild ID had an almost threefold increased likelihood of maltreatment allegations $(\mathrm{HR}=2.73,95 \% \mathrm{CI}: 2.45-3.04)$, and children with mild-moderate ID were at twofold increased likelihood of allegations (HR=2.01, 95\%CI:1.85-2.17). The risk associated with severe ID 
did not differ significantly from children without ID (HR=1.30, 95\%CI:0.95-1.79). When broken down by type of maltreatment allegation the findings were relatively consistent except that for children with severe ID they were at increased risk of neglect (appendix).

Among children with ID, a supplementary analysis found an increased maltreatment risk for children for whom the recorded cause of disability was postnatal injury $(\mathrm{HR}=5.14$, 95\%CI:2.99-8.83), prenatal exposure to alcohol (HR=2.01, 95\%CI:1.30-3.11), other birth defects(HR=9.49, 95\%CI:2.20-41.06) and cultural-familial (HR=4.13, 95\% CI(3.01-5.66).

\section{Comorbidity}

Comorbidity was common. Of the 8,551 children with ID, 5,350 (62.6\%) also have at least one of the following: birth defect/cerebral palsy, autism, conduct disorder or a mental/behavioural diagnosis. The presence of comorbid ID significantly increased the likelihood of having a maltreatment allegation for children with birth defect/cerebral palsy, autism or mental health and behavioural disorders (Table 5). Children with autism but no ID showed a non-significant increased risk probably due to volatility of estimates due to small numbers.

\section{Discussion}

Children with disabilities make up $10.4 \%$ of the WA population however they account for one in four maltreatment allegations and one in three substantiated allegations. This disproportionate representation of children with disabilities in maltreatment allegations are consistent with international findings ${ }^{9}$. Importantly the increased risk of maltreatment allegations was not consistent across all disability types. Over-represented groups included children with ID, conduct disorder and mental/behavioural disorders. 
Prior studies have included various disability types but there is no consistent method for defining and grouping disability types, which reduces comparability. Also different countries may have different thresholds and processes around child maltreatment allegations which reduces comparability. Nevertheless, comparisons with previous studies shed light on some consistent findings. Unadjusted results show significantly elevated risk of allegations for all disability types except DS, with a more than threefold increased risk of allegations for mental/behavioural disorders, conduct disorder, and ID. After adjusting for risk factors, children with ID, mental/behavioural problems and conduct disorder continued to have increased risk of allegations and substantiated allegations, consistent with previous research $^{4,9,10}$. Likewise children with ID continued to have increased risk of allegations, consistent with some but not all previous population studies ${ }^{4,9}$.

In contrast, after adjustment children with autism, DS and birth defects/cerebral palsy showed no increased risk for an allegation. However for substantiated maltreatment children with birth defects/cerebral palsy had a slightly increased risk which just reached significance. Our results of no increased risk for autism and DS are consistent with previous research despite different lengths of follow-up ${ }^{4,9}$. However our finding of no increased risk for spina bifida or cleft lip and/or palate after adjustment was opposite to previous findings ${ }^{15}$.

Possible explanations for the lower risk for children with DS and autism include that these disabilities are comparatively well recognised, understood and supported. Parents tended to be older, better off socio-economically, and for DS, the ready availability of pre-natal screening in WA means most parents have had the opportunity for prenatal diagnosis and the choice to continue with the pregnancy ${ }^{19}$. 
We cannot specifically address the directionality of maltreatment and disability in our study. However the stronger relationship between disability types that could be caused by or share a pathway with maltreatment is consistent with studies that found the relationship with maltreatment was stronger (e.g. Sullivan ${ }^{9}$ ) or only present (e.g. Spencer ${ }^{4}$ ) for disabilities such as conduct disorder, mental/behavioural problems, and ID. Together with our examination of the recorded cause of intellectual disability, finding increased risk for postnatal injury, prenatal exposure to alcohol, and cultural-familial causes lends further support to this. As an example of potential complexities, the case of maternal alcohol use during pregnancy (causing ID) and continuing following birth may impact parenting a child with complex needs resulting in child protection involvement. This should be examined in future research.

Regardless of causality, the disability types most strongly associated with maltreatment often co-occurred with a constellation of other risk factors such as parents who are young or who have been hospitalised for mental health or substance use, and living in more disadvantaged neighbourhoods. These families already face additional stressors and have fewer resources to access services for their children's special needs.

The inverse relationship between severity of ID and risk of maltreatment is consistent with other research ${ }^{3}$. It has been suggested that where children's disabilities are more profound, parents may have more realistic expectations, or children may be less able to function in ways that are provocative (e.g. talking back). Furthermore, clustering of mild ID within families is relatively common, and linked to socio-economic disadvantage ${ }^{20}$. In combination with our finding that ID with cultural-familial causes was associated with increased maltreatment it may be that a number of children with mild ID are more likely to experience maltreatment 
because they have a higher risk family profile. It is important that qualitative research investigates further factors that may increase risk and identify support strategies and interventions which may assist families.

The relationship between disability and child maltreatment was partially attenuated after adjusting for demographic and psychosocial risk factors. These findings indicate that disability is an important risk factor for maltreatment, but not all disabled children should be considered at increased risk, and that other risk factors at the child, family and neighbourhood level also play an important role. From our analyses socioeconomic disadvantage, teenage parents, maternal mental health and substance use admissions were strong risk factors for maltreatment. Factors at these different levels need to be considered when assessing the needs of families to ameliorate risks.

Although the use of administrative data allows complete case ascertainment of children with maltreatment allegations from birth onwards in WA it does have limitations. Obviously maltreatment will only be included if it is reported. While we have comprehensively ascertained disability from a number of population level data sources not all children with disabilities will be identified. Co-morbidities will also be under-ascertained as the MHIS only captures one diagnosis. During the study period it is expected that there would be changes in the prevalence of diagnoses over time which would have impacted upon the prevalence of ICD codes. For example previous research found a rise in the prevalence of autism diagnoses in 1994 with the introduction of the Diagnostic and Statistical Manual Version IV and in 1997 with the formalisation of assessment procedures $^{21}$. In addition a number of important variables could not be obtained using our data including: the child's level of functioning; age of diagnosis; type and amount of support services families are receiving; family functioning; 
and parents' own disability status. The other issue is the timing of the onset of disability/condition in relation to maltreatment to provide further evidence of directionality, whether maltreatment may be a cause for some conditions (e.g. conduct disorder) or contributes as a risk factor to maltreatment. We also cannot rule out that children with disabilities are likely to have increased service use, therefore higher scrutiny and increased likelihood to be reported for maltreatment which should be considered in future research.

The prevalence of disabilities in the child protection population suggests the need for awareness by agencies of the scope of issues faced by children in the system and interagency collaboration to ensure children's complex needs are met. In addition supports are needed for families of children with disabilities not only to assist in meeting the child's health and developmental needs, but also to support parents in managing the often more complex parenting environment, including dealing with challenging behaviour. Research indicates that family-centred care with coordination of services, continuity of care and respite care are important factors in reducing child protection risk ${ }^{22,23}$. As signatories to the United Nations Conventions on the Rights of the Child and Rights of Persons with Disabilities, governments have committed to assist parents in the performance of their child rearing responsibilities and that that persons with disabilities and their family members should receive the necessary assistance to enable families to contribute towards the full and equal enjoyment of the rights of persons with disabilities. This highlights the important role governments and society have in ensuring that children with disabilities and their families have the appropriate services and support structures in place to enable them to achieve their full potential and ensure their wellbeing. 


\section{Acknowledgements}

The authors acknowledge the partnership of the Western Australian Government Departments of Health, Child Protection, Education, Disability Services, Corrective Services and Attorney General who provided support as well as data for this project. This paper does not necessarily reflect the views of the government departments involved in this research. We would also like to thank the Western Australian Data Linkage Branch for linking the data. 


\section{References}

1. World Health Organisation. World Report on Disability. Geneva: World Health Organisation;2011.

2. Sullivan PM, Knutson JF. The association between child Maltreatment and disabilities in a hospitalbased epidemiological study. Child Abuse \& Neglect. 1998;22(4):271-288.

3. Verdugo MA, Bermejo BG, Fuertes J. The maltreatment of intellectually handicapped children and adolescents. Child Abuse \& Neglect. 1995;19(2):205-215.

4. Spencer N, Devereux E, Wallace A, et al. Disabling conditions and registration for child abuse and neglect: A population-based study. Pediatrics. 2005;116(3):609-613.

5. Westcott HL, Jones DPH. Annotation: The abuse of disabled children. Journal of Child Psychology and Psychiatry. 1999;40(4):497-506.

6. O'Donnell M, Nassar N, Leonard H, et al. Characteristics of non-Aboriginal and Aboriginal children and families with substantiated maltreatment: A population-based study. International Journal of Epidemiology. 2010;39:921-928.

7. Kendall-Tackett K, Lyon T, Taliaferro G, Little L. Why child maltreatment researchers should include children's disability status in their maltreatment studies. Child Abuse \& Neglect.

2005;29(2):147-151.

8. Fisher M, Hodapp R, Dykens E. Child abuse among children with disabilities: What we know and what we need to know. International Review of Research in Mental Retardation. 2008;35:251-289.

9. Sullivan PM, Knutson JF. Maltreatment and disabilities: A population-based epidemiological study. Child Abuse \& Neglect. 2000;24(10):1257-1273.

10. Jaudes PK, Mackey-Bilaver L. Do chronic conditions increase young children's risk of being maltreated? Child Abuse \& Neglect. 2008;32(7):671-681.

11. Bower C, Baynam G, Rudy E, et al. Report of the Western Australian Register of Developmental Anomalies 1980-2014. Perth: King Edward Memorial Hospital;2015.

12. Petterson B, Leonard H, Bourke J, et al. IDEA (Intellectual Disability Exploring Answers): A population-based database for intellectual disability in Western Australia. Annals of Human Biology. 2005;32(2):237-243.

13. Bourke J, De Klerk N, Smith T, Leonard H. Population-based prevalence of intellectual disability and autism spectrum disorder in Western Australia. Medicine 2016;95(21):e3737.

14. Australian Bureau of Statistics. Children with a disability. Australian Social Trends, Jun 2012. Canberra2012.

15. Van Horne BS, Moffitt KB, Canfield MA, et al. Maltreatment of children under age 2 with specific birth defects: A population-based study. Pediatrics. 2015;136(6):e1504-e1512.

16. Kelman C, Bass A, Holman C. Research use of linked health data - a best practice protocol. Australian and New Zealand Journal of Public Health. 2002;26(3):251-255.

17. Department of Health. Data linkage - making the right connections. 2016. http://www.datalinkagewa.org.au/sites/default/files/Data\%20Linkage\%20Branch\%20-\%20Linkage\%20Quality.pdf Accessed 14/12/2016.

18. Australian Bureau of Statistics. Socio-Economic Indexes for Areas (SEIFA) - Technical Paper. Canberra: Australian Bureau of Statistics;2008.

19. Collins VR, Muggli EE, Riley M, Palma S, Halliday JL. Is Down Syndrome a disappearing birth defect? Journal of Pedatrics 2008;152(152):20-24.

20. Bower C, Leonard H, Petterson B. Intellectual disability in Western Australia. Journal of Paediatrics and Child Health. 2000;36(3):213-215.

21. Nassar N, Dixon G, Bourke J, et al. Autism spectrum disorders in young children: effect of changes in diagnostic practices. International Journal of Epidemiology. 2009;38(1245-1254).

22. O'Brien J, O'Brien J. Planned respite care: Hope for families under pressure. Australian Journal of Social Issues. 2001;36(1):51-65.

23. Hodgetts S, Nicholas D, Zwaigenbaum L, McConnell D. Parents' and professionals' perceptions of family centered care for children with autism spectrum disorder across service sectors. Social Science \& Medicine. 2013;96:138-146. 
Table 2. Characteristics of study population and level of child protection involvement

\begin{tabular}{|c|c|c|c|c|c|c|c|c|c|}
\hline \multirow[t]{2}{*}{ Characteristic } & \multirow[t]{2}{*}{ Total } & \multicolumn{2}{|c|}{ No Allegation } & \multicolumn{2}{|c|}{ Any Allegation } & \multicolumn{2}{|c|}{$\begin{array}{l}\text { Any Substantiated } \\
\text { Allegation }\end{array}$} & \multicolumn{2}{|c|}{$\begin{array}{l}\text { Entered out-of-home } \\
\text { care }\end{array}$} \\
\hline & & $\mathbf{N}$ & $\%$ & $\mathbf{N}$ & $\%$ & $\mathbf{N}$ & $\%$ & $\mathbf{N}$ & $\%$ \\
\hline Number & 524534 & 500518 & & 24016 & & 11560 & & 5596 & \\
\hline \multicolumn{10}{|l|}{ Sex } \\
\hline Male & 268651 & 257108 & $51.4 \%$ & 11543 & $48.1 \%$ & 5472 & $47.3 \%$ & 2810 & $50.2 \%$ \\
\hline Female & 255831 & 243362 & $48.6 \%$ & 12469 & $51.9 \%$ & 6088 & $52.6 \%$ & 2786 & $49.8 \%$ \\
\hline \multicolumn{10}{|l|}{ Aboriginality } \\
\hline Non-Aboriginal & 492740 & 475379 & $95.0 \%$ & 17361 & $72.3 \%$ & 7771 & $67.2 \%$ & 3506 & $62.7 \%$ \\
\hline Aboriginal & 31612 & 24975 & $5.0 \%$ & 6637 & $27.6 \%$ & 3779 & $32.7 \%$ & 2085 & $37.3 \%$ \\
\hline Missing & 182 & 164 & $0.03 \%$ & 18 & $0.1 \%$ & 10 & $0.1 \%$ & 5 & $0.09 \%$ \\
\hline \multicolumn{10}{|l|}{ Socio-economic status } \\
\hline 1 (most disadvantaged) & 120565 & 37560 & $7.5 \%$ & 11506 & $47.9 \%$ & 5811 & $50.3 \%$ & 2903 & $51.9 \%$ \\
\hline 2 & 120126 & 81247 & $16.2 \%$ & 5805 & $24.2 \%$ & 2749 & $23.4 \%$ & 1335 & $23.9 \%$ \\
\hline 3 & 99811 & 66313 & $13.5 \%$ & 3344 & $13.9 \%$ & 1550 & $13.4 \%$ & 726 & $13.0 \%$ \\
\hline 4 & 94009 & 136417 & $27.3 \%$ & 2097 & $8.7 \%$ & 923 & $8.0 \%$ & 420 & $7.5 \%$ \\
\hline 5 (least disadvantaged) & 87330 & 177067 & $35.4 \%$ & 1120 & $4.7 \%$ & 445 & $3.8 \%$ & 173 & $3.1 \%$ \\
\hline Missing & 2693 & 1914 & $0.4 \%$ & 144 & $0.6 \%$ & 82 & $0.7 \%$ & 39 & $0.7 \%$ \\
\hline \multicolumn{10}{|l|}{ Disability Type } \\
\hline Intellectual Disability & 8551 & 6952 & $1.4 \%$ & 1599 & $6.7 \%$ & 905 & $7.8 \%$ & 527 & $9.4 \%$ \\
\hline Down Syndrome & 552 & 521 & $0.1 \%$ & 31 & $0.1 \%$ & 15 & $0.1 \%$ & 8 & $0.1 \%$ \\
\hline Birth Defect/Cerebral Palsy & 30090 & 28501 & $5.7 \%$ & 1589 & $6.6 \%$ & 860 & $7.4 \%$ & 498 & $8.9 \%$ \\
\hline Autism & 2253 & 2078 & $0.4 \%$ & 175 & $0.7 \%$ & 89 & $0.8 \%$ & 56 & $1.0 \%$ \\
\hline Conduct disorder & 3924 & 2846 & $0.6 \%$ & 1078 & $4.5 \%$ & 573 & $5.0 \%$ & 318 & $5.7 \%$ \\
\hline Mental and behavioural disorder & 19813 & 16062 & $3.2 \%$ & 3751 & $15.6 \%$ & 2073 & $17.9 \%$ & 1004 & $17.9 \%$ \\
\hline Any disability & 54535 & 48324 & $9.7 \%$ & 6211 & $25.9 \%$ & 3352 & $29.0 \%$ & 1709 & $30.5 \%$ \\
\hline \multicolumn{10}{|l|}{ Maternal age } \\
\hline$<20$ & 30019 & 25194 & $5.0 \%$ & 4825 & $20.1 \%$ & 2406 & $20.8 \%$ & 1162 & $20.8 \%$ \\
\hline
\end{tabular}




\begin{tabular}{|c|c|c|c|c|c|c|c|c|c|}
\hline $20-29$ & 252817 & 239044 & $47.8 \%$ & 13773 & $57.3 \%$ & 6638 & $57.4 \%$ & 3162 & $56.5 \%$ \\
\hline $30+$ & 241642 & 236228 & $47.2 \%$ & 5414 & $22.5 \%$ & 2516 & $21.8 \%$ & 1272 & $22.7 \%$ \\
\hline Missing & 56 & 52 & $0.01 \%$ & 4 & $0.02 \%$ & 0 & $0.0 \%$ & 0 & $0.0 \%$ \\
\hline \multicolumn{10}{|l|}{ Paternal age } \\
\hline$<20$ & 9522 & 8107 & $1.6 \%$ & 1415 & $5.9 \%$ & 687 & $5.9 \%$ & 327 & $5.8 \%$ \\
\hline $20-29$ & 175262 & 165343 & $33.0 \%$ & 9919 & $41.3 \%$ & 4649 & $40.2 \%$ & 2074 & $37.1 \%$ \\
\hline $30+$ & 314549 & 307078 & $61.4 \%$ & 7471 & $31.1 \%$ & 3257 & $28.2 \%$ & 1518 & $27.1 \%$ \\
\hline Missing & 25201 & 19990 & $4.0 \%$ & 5211 & $21.7 \%$ & 2967 & $25.7 \%$ & 1677 & $30.0 \%$ \\
\hline \multicolumn{10}{|l|}{ Gestational age } \\
\hline$<37$ weeks & 38702 & 35767 & $7.1 \%$ & 2935 & $12.2 \%$ & 1606 & $13.9 \%$ & 945 & $16.9 \%$ \\
\hline $37+$ weeks & 485157 & 464117 & $92.7 \%$ & 21040 & $87.6 \%$ & 9933 & $85.9 \%$ & 4642 & $83.0 \%$ \\
\hline \multicolumn{10}{|c|}{ Birthweight for Gestational Age } \\
\hline Below 10th percentile & 52489 & 48271 & $9.6 \%$ & 4218 & $17.6 \%$ & 2182 & $18.9 \%$ & 1164 & $20.8 \%$ \\
\hline Above 10th percentile & 471322 & 451566 & $90.2 \%$ & 19756 & $82.3 \%$ & 9357 & $80.9 \%$ & 4423 & $79.0 \%$ \\
\hline \multicolumn{10}{|l|}{ Marital Status } \\
\hline Single & 51697 & 44091 & $8.8 \%$ & 7606 & $31.7 \%$ & 4000 & $34.6 \%$ & 2223 & $39.7 \%$ \\
\hline Married/Defacto & 470751 & 454529 & $90.8 \%$ & 16222 & $67.5 \%$ & 7436 & $64.3 \%$ & 3302 & $59.0 \%$ \\
\hline Missing & 2086 & 1898 & $0.4 \%$ & 188 & $0.8 \%$ & 124 & $1.1 \%$ & 71 & $1.3 \%$ \\
\hline \multicolumn{10}{|c|}{ Maternal MH related admission } \\
\hline Yes & 86956 & 75459 & $15.1 \%$ & 11497 & $47.9 \%$ & 6153 & $53.2 \%$ & 3573 & $63.8 \%$ \\
\hline No & 437578 & 425059 & $84.9 \%$ & 12519 & $52.1 \%$ & 5407 & $46.8 \%$ & 2023 & $36.2 \%$ \\
\hline \multicolumn{10}{|c|}{ Maternal substance-related admission } \\
\hline Yes & 41150 & 31278 & $6.3 \%$ & 9872 & $41.1 \%$ & 5756 & $49.8 \%$ & 3597 & $64.3 \%$ \\
\hline No & 483384 & 469240 & $93.7 \%$ & 14144 & $58.9 \%$ & 5804 & $50.2 \%$ & 1999 & $26.9 \%$ \\
\hline \multicolumn{10}{|c|}{ Paternal MH related admission } \\
\hline Yes & 46689 & 41323 & $8.3 \%$ & 5366 & $22.3 \%$ & 2756 & $23.8 \%$ & 1506 & $26.9 \%$ \\
\hline No & 477845 & 459195 & $91.7 \%$ & 18650 & $77.6 \%$ & 8804 & $76.2 \%$ & 4090 & $73.1 \%$ \\
\hline \multicolumn{10}{|c|}{ Paternal substance-related admission } \\
\hline Yes & 43431 & 37212 & $7.4 \%$ & 6219 & $25.9 \%$ & 3371 & $29.2 \%$ & 1932 & $34.5 \%$ \\
\hline No & 481103 & 463306 & $92.6 \%$ & 17797 & $74.1 \%$ & 8189 & $70.8 \%$ & 3664 & $65.5 \%$ \\
\hline
\end{tabular}


Table 3. Risk of maltreatment allegation and substantiated maltreatment allegation by disability.

\section{Risk of Maltreatment Allegation}

\section{Crude HR Adjusted HR}

Characteristic

$$
\text { Sex }
$$

Sex

Male

Ref

$1.14(1.12-1.17)$

Adjusted HR (Six No)*

Disability Category)**

Risk of Substantiated Maltreatment Allegation

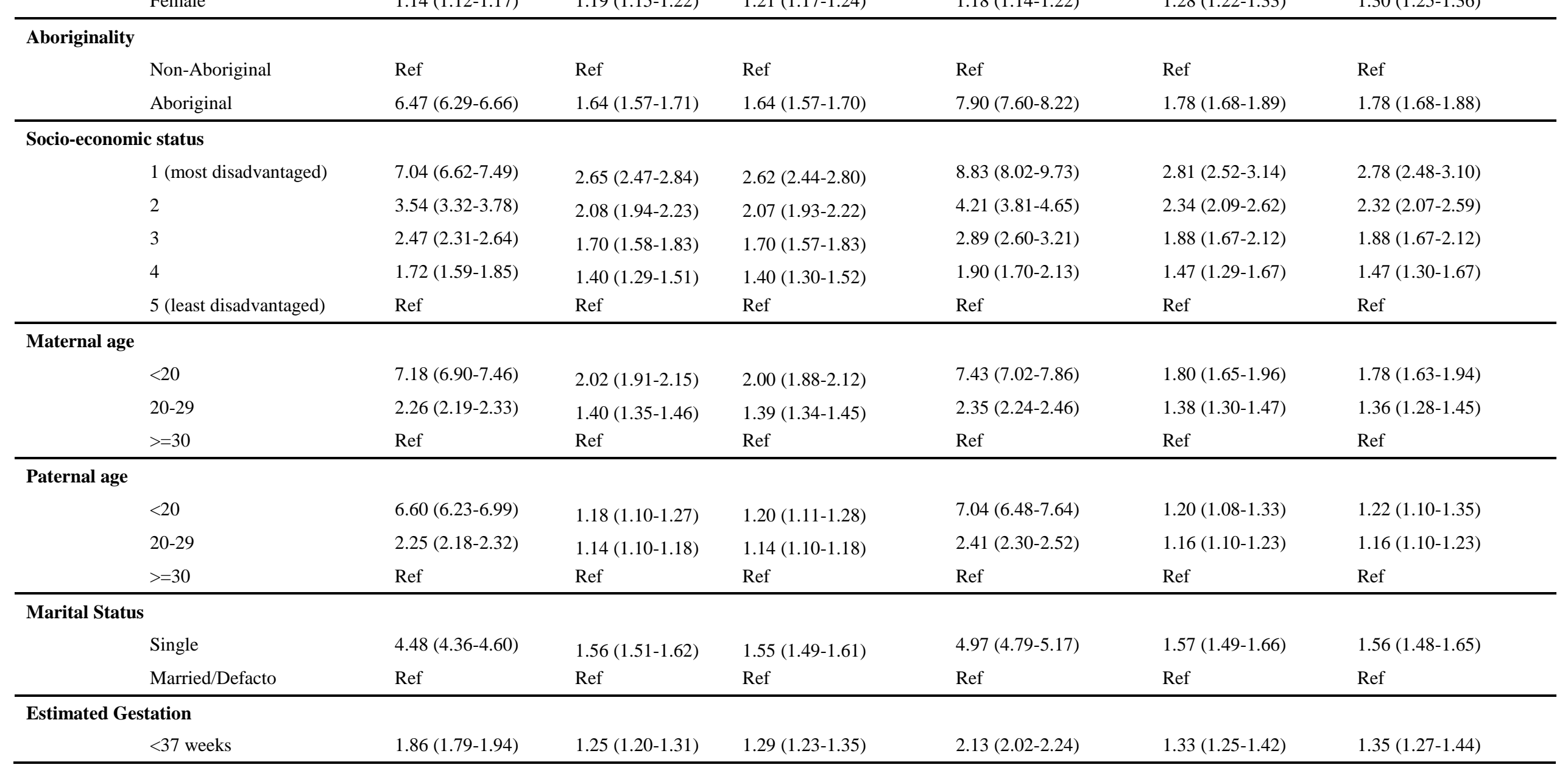




\begin{tabular}{|c|c|c|c|c|c|c|}
\hline \multicolumn{7}{|l|}{ Birth Weight for Gestational Age } \\
\hline$<10^{\text {th }}$ Percentile & $1.90(1.84-1.96)$ & $1.23(1.18-1.28)$ & $1.23(1.18-1.28)$ & $2.06(1.96-2.15)$ & $1.26(1.19-1.33)$ & $1.25(1.18-1.33)$ \\
\hline \multicolumn{7}{|c|}{ Maternal mental health-related admission } \\
\hline Yes & $4.77(4.65-4.90)$ & $2.32(2.24-2.39)$ & $2.28(2.21-2.36)$ & $5.76(5.57-5.98)$ & $2.47(2.35-2.59)$ & $2.43(2.31-2.55)$ \\
\hline \multicolumn{7}{|c|}{ Maternal substance-related admission } \\
\hline Yes & $8.61(8.39-8.84)$ & $2.82(2.72-2.92)$ & $2.78(2.69-2.89)$ & $11.68(11.26-12.12)$ & $3.36(3.19-3.54)$ & $3.33(3.16-3.50)$ \\
\hline \multicolumn{7}{|c|}{ Paternal mental health-related admission } \\
\hline Yes & $2.92(2.83-3.01)$ & $1.68(1.62-1.74)$ & $1.65(1.59-1.71)$ & $3.12(2.99-3.26)$ & $1.69(1.61-1.78)$ & $1.66(1.58-1.75)$ \\
\hline \multicolumn{7}{|c|}{ Paternal substance-related admission } \\
\hline Yes & $3.85(3.74-3.97)$ & $1.86(1.79-1.93)$ & $1.85(1.78-1.91)$ & $4.45(4.28-4.64)$ & $2.10(1.99-2.21)$ & $2.09(1.98-2.20)$ \\
\hline \multicolumn{7}{|l|}{ Any Disability } \\
\hline Yes & $2.64(2.56-2.72)$ & $1.74(1.68-1.80)$ & & $3.09(2.97-3.22)$ & $1.89(1.80-1.98)$ & \\
\hline \multicolumn{7}{|l|}{ Intellectual Disability } \\
\hline Yes & $3.86(3.67-4.06)$ & & $2.14(2.00-2.28)$ & $4.51(4.21-4.83)$ & & $2.15(1.96-2.35)$ \\
\hline \multicolumn{7}{|l|}{ Down Syndrome } \\
\hline Yes & $1.15(0.80-1.66)$ & & $0.69(0.46-1.02)$ & $1.08(0.63-1.86)$ & & $0.48(0.25-0.93)$ \\
\hline \multicolumn{7}{|l|}{ Birth Defect/Cerebral Palsy } \\
\hline Yes & $1.12(1.06-1.18)$ & & $0.99(0.93-1.05)$ & $1.27(1.19-1.37)$ & & $1.10(1.01-1.20)$ \\
\hline \multicolumn{7}{|l|}{ Autism } \\
\hline Yes & $1.53(1.32-1.78)$ & & $0.74(0.63-0.89)$ & $1.65(1.34-2.03)$ & & $0.87(0.68-1.11)$ \\
\hline \multicolumn{7}{|l|}{ Conduct disorder } \\
\hline Yes & $5.14(4.83-5.47)$ & & $1.84(1.70-1.98)$ & $5.57(5.12-6.06)$ & & $1.74(1.56-1.93)$ \\
\hline \multicolumn{7}{|l|}{ Mental and behavioural disorder } \\
\hline Yes & $3.69(3.56-3.82)$ & & $1.62(1.55-1.69)$ & $4.37(4.17-4.59)$ & & $1.74(1.64-1.85)$ \\
\hline
\end{tabular}

* Adjusted by sex, Aboriginality, socioeconomic status, maternal age, paternal age, marital status, estimated gestation, birth weight for generational age, parental mental health-related admissions, parental substance-related admissions and whether they had a disability.

** Adjusted by sex, Aboriginality, socioeconomic status, maternal age, paternal age, marital status, estimated gestation, birth weight for generational age, parental mental healthrelated admissions, parental substance-related admissions and disability groups. 
Table 4. Risk of maltreatment allegation by severity of intellectual disability

\begin{tabular}{lll}
\hline Severity of ID & Number & Multivariate Hazards Ratio* \\
\hline Borderline-Mild & 2775 & $2.73(2.45-3.04)$ \\
Mild-Moderate & 4077 & $2.01(1.85-2.17)$ \\
Severe & 552 & $1.30(0.95-1.79)$ \\
Unknown & 1147 & $1.57(1.22-2.03)$ \\
No Intellectual Disability & 515983 & Ref \\
\hline
\end{tabular}

\footnotetext{
* Adjusted by sex, Aboriginality, socioeconomic status, maternal age, paternal age, marital status, estimated gestation, birth weight for generational age, parental mental health-related admissions, and parental substance-related admissions.
}

Table 5. Risk of maltreatment allegation by comorbidity with intellectual disabilities

\begin{tabular}{lll}
\hline Disability Group (with and without ID)\# & Number & Multivariate Hazards Ratio* \\
\hline Down Syndrome & 552 & $0.77(0.51-1.17)$ \\
\hline Birth defect/Cerebral Palsy with ID & 2606 & $1.78(1.54-2.04)$ \\
\hline Birth defect/Cerebral Palsy no ID & 27484 & $0.96(0.90-1.02)$ \\
\hline Autism with ID & 2120 & $1.21(1.02-1.45)$ \\
\hline Autism no ID & 133 & $1.71(0.92-3.19)$ \\
\hline Conduct with ID & 485 & $1.83(1.51-2.23)$ \\
\hline Conduct no ID & 3439 & $1.92(1.78-2.08)$ \\
\hline Mental disorders with ID & 1587 & $2.13(1.86-2.43)$ \\
\hline Mental disorders no ID & 18226 & $1.63(1.55-1.70)$ \\
\hline
\end{tabular}

* Adjusted by sex, Aboriginality, socioeconomic status, maternal age, paternal age, marital status, estimated gestation, birth weight for generational age, parental mental health-related admissions, and parental substance-related admissions.

\#Reference group is children not in that disability group. 
Appendix Table. Demographics associated with Disability Group.

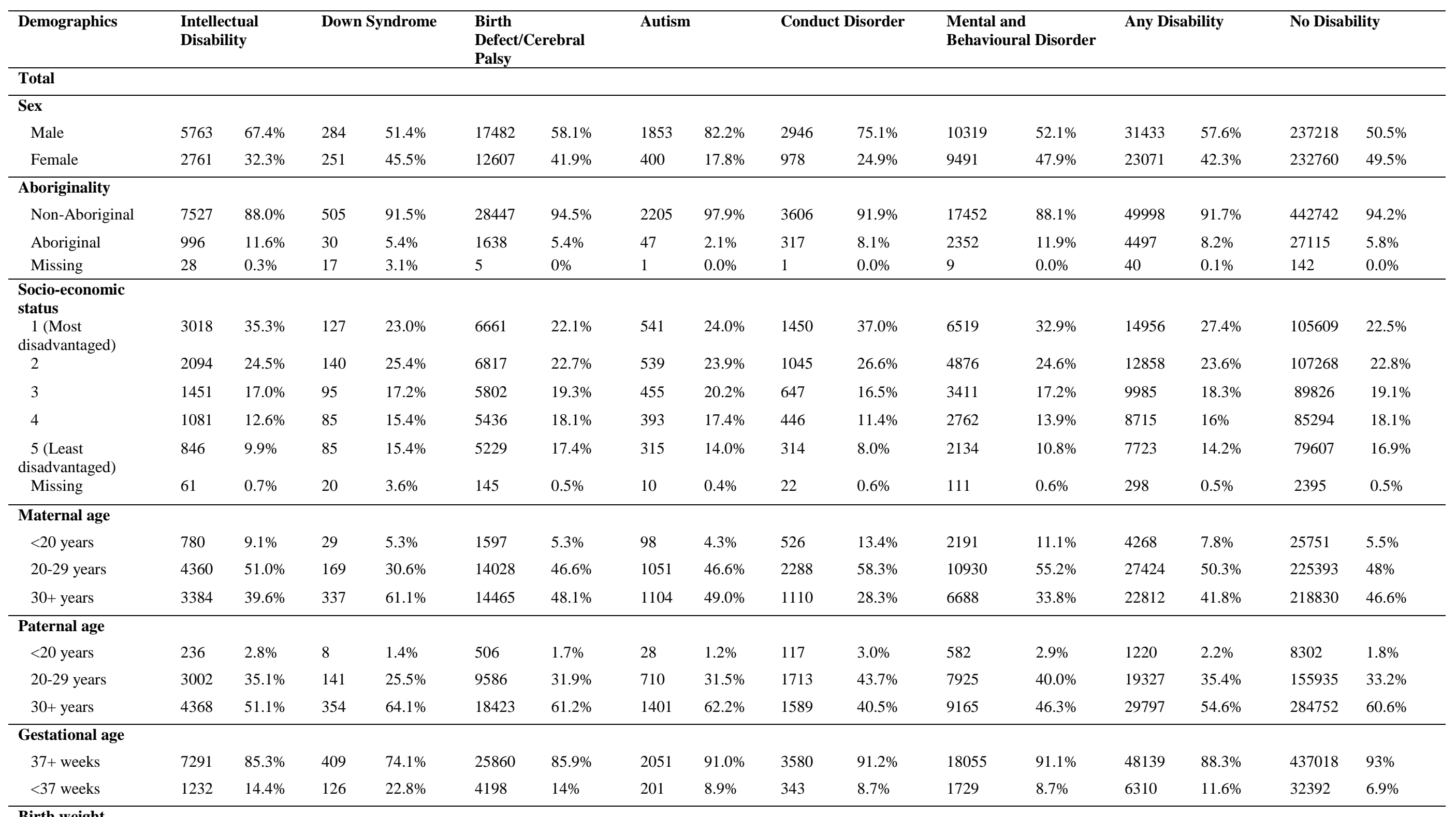




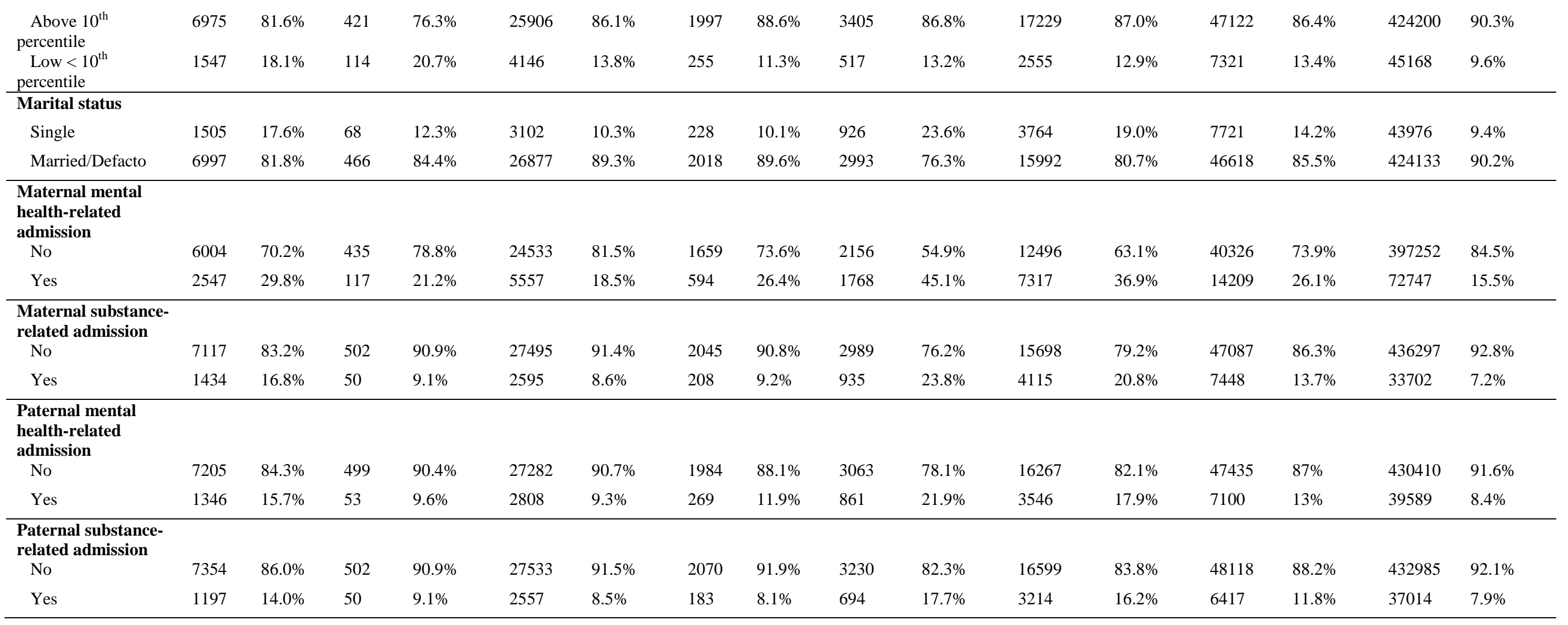


Supplementary Appendix. Cox regression: Risk of entering out-of-home care by disability

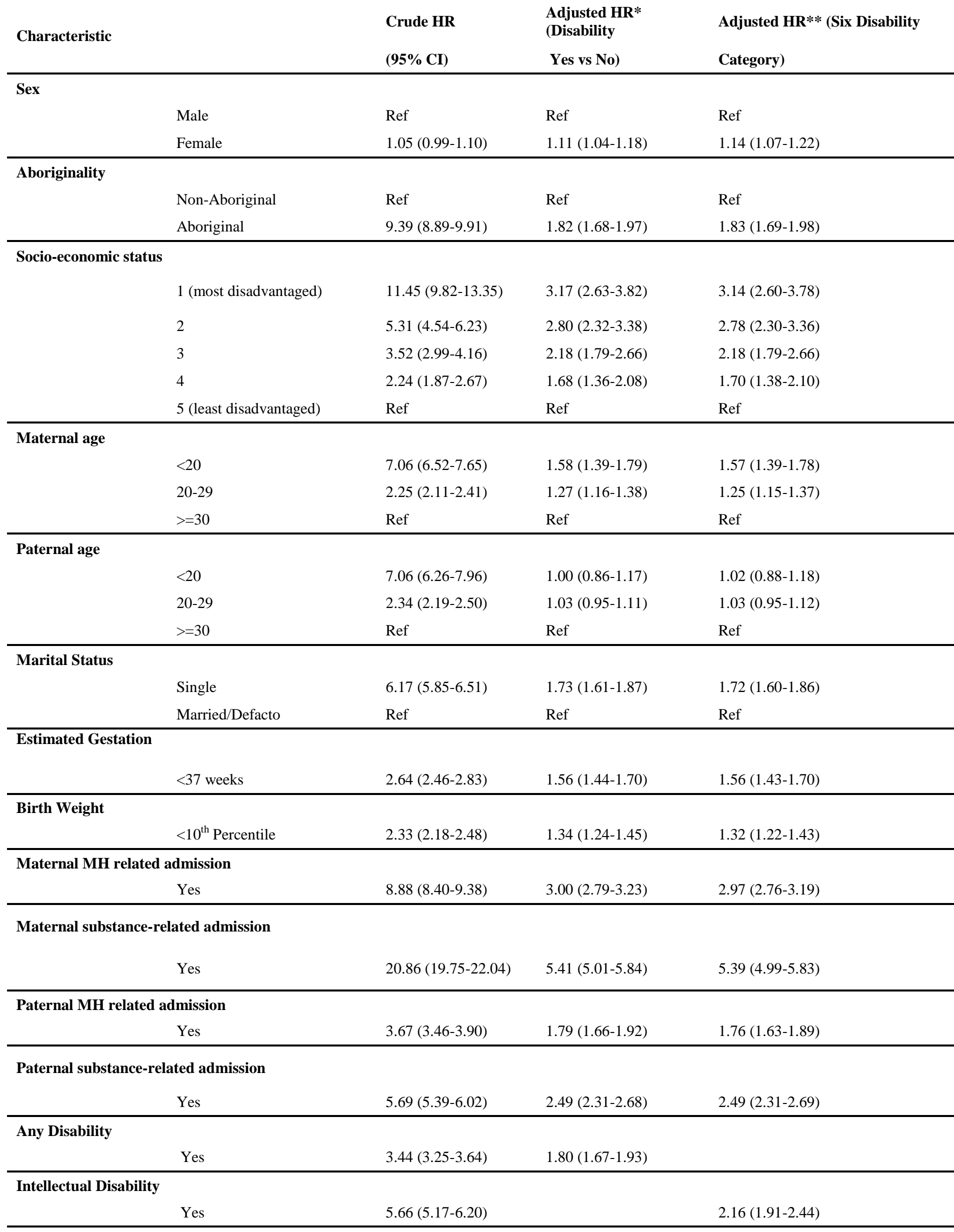

Down Syndrome 


\title{
Birth Defect/Cerebral Palsy
}

Yes

$1.57(1.43-1.72)$

$1.32(1.18-1.49)$

\section{Autism}

Yes

$2.18(1.67-2.83)$

$1.11(0.80-1.53)$

\section{Conduct disorder}

Yes

$6.79(6.05-7.60)$

$1.83(1.58-2.12)$

\section{Mental and behavioural disorder}

$$
\text { Yes }
$$

1.44 (1.31-1.58)

\begin{abstract}
* Adjusted by sex, Aboriginality, socioeconomic status, maternal age, paternal age, marital status, estimated gestation, birth weight for generational age, parental mental health-related admissions, parental substance-related admissions and whether they had a disability.

** Adjusted by sex, Aboriginality, socioeconomic status, maternal age, paternal age, marital status, estimated gestation, birth weight for generational age, parental mental health-related admissions, parental substance-related admissions and disability groups
\end{abstract}


Supplementary Appendix. Cox regression: Adjusted risk by type of maltreatment allegation by disability

Type of Disability\#

Sexual Abuse

Physical Abuse

Neglect

\section{Adjusted HR (95\%}

Adjusted HR (95\%

CI)*

Adjusted HR (95\%

CI)*

\begin{tabular}{ll}
\hline Intellectual Disability & $2.78(2.3$ \\
\hline Down Syndrome & $* *$ \\
\hline Birth Defect/Cerebral Palsy & $0.90(0.7$ \\
\hline Autism & $0.34(0.1$ \\
\hline Conduct disorder & $1.98(16$ \\
\hline Mental and behavioural disorder & $2.52(2.2$ \\
\hline $\begin{array}{l}* \\
\text { birth weight for generational age, parental mental he } \\
\text { other types of disability. } \\
\text { **Numbers too small to report estimates } \\
\text { \#Reference group is children without that disability }\end{array}$
\end{tabular}

Supplementary Appendix. Cox regression: Adjusted risk by type of maltreatment allegation by severity of intellectual disability

\begin{tabular}{llll} 
Severity of ID & $\begin{array}{l}\text { Sexual Abuse } \\
\text { Adjusted HR }(\mathbf{9 5 \%}\end{array}$ & $\begin{array}{l}\text { Physical Abuse } \\
\text { CI)* }\end{array}$ & $\begin{array}{l}\text { Neglect } \\
\text { CI)* }\end{array}$ \\
\hline Borderline-Mild & $3.79(2.94-4.88)$ & $2.63(2.05-3.39)$ & $\begin{array}{l}\text { Adjusted HR (95\% } \\
\text { CI)* }\end{array}$ \\
Mild-Moderate & $2.53(2.06-3.12)$ & $2.06(1.70-2.49)$ & $1.64(1.30-4.83$ \\
Severe & $0.31(0.04-2.20)$ & $1.37(0.65-2.91)$ & $2.03(1.17-3.54)$ \\
Unknown & $2.68(1.36-5.28)$ & $2.38(1.43-3.97)$ & $2.53(1.54-4.15)$ \\
No Intellectual Disability & Reference & Reference & Reference \\
\hline
\end{tabular}

* Adjusted by sex, Aboriginality, socioeconomic status, maternal age, paternal age, marital status, estimated gestation, birth weight for generational age, parental mental health-related admissions, parental substance-related admissions. 